Jurnal Health Sains: p-ISSN: 2723-4339 e-ISSN: 2548-1398

Vol. 2, No. 5, Mei 2021

\title{
PENGARUH MODEL DETEKSI DINI KARTU KENDALI STROKE TERHADAP KEMAMPUAN KLIEN DALAM PENGENDALIAN FAKTOR RESIKO STROKE
}

\section{Tarwoto}

Politeknik Kesehatan Kemenkes Jakarta, Indonesia

Email: tarwoto_spp@yahoo.com

\begin{tabular}{l}
\hline ARTIKEL INFO \\
\hline Tanggal diterima: 5 Mei 2021 \\
Tanggal revisi: 15 Mei 2021 \\
Tanggal yang disetujui: $25 \mathrm{Mei}$ \\
2021
\end{tabular}

Keywords:

stroke; stroke risk factors;

stroke control card education

$(K K S)$

\begin{abstract}
Stroke is a degenerative disease that currently occurs as much as it occurs. This is due to changes in people's unhealthy lifestyles, such as reduced activity, unhealthy diet, lack of rest, and many other factors. The general purpose of this study is to identify the influence of stroke control card education on the client's ability to control stroke risk factors. In this study using Quasi-Experimental with Pretest-Posttest with Control Group Desaign approach. In this design, researchers conducted an assessment on the control group and intervention group before stroke control card (KKS) education. The intervention group was treated with KKS education, then measured (post test) the level of knowledge ability and attitude to control stroke risk factors while the control group was not treated but measured. This study is titled the influence of early detection models through stroke control card education on the client's ability to control stroke risk factors. The study sampled 80 people for the control group and 80 people in the intervention group with the criteria of the sample of patients with stroke risk factors. Research site in South Jakarta with a research duration of 4 months.
\end{abstract}

\begin{abstract}
ABSTRAK
Stroke merupakan penyakit degeneratif yang saat ini semankin banyak terjadi. Hal ini disebabkan adanya perubahan gaya hidup masyarakat yang kurang sehat, seperti makin berkurangnya aktivitas, pola makan yang tidak sehat, istirahat yang kurang, dan banyak faktor lainnya. Tujuan umum penelitian ini adalah mengidentifikasi pengaruh edukasi kartu kendali stroke terhadap kemampuan klien dalam pengendalian faktor resiko stroke. Pada penelitian ini menggunakan Quasi-Experimental dengan pendekatan Pretest-Posttest with Control Group Desaign. Pada desain ini peneliti melakukan penilaian pada kelompok kontrol dan kelompok intervensi sebelum edukasi Kartu Kendali Stroke (KKS). Kelompok intervensi dilakukan perlakukan dengan edukasi KKS, kemudian diukur (post test) tingkat kemampuan pengetahuan dan sikap terhadap pengendalian factor risiko stroke sedangkan kelompok kontrol tidak dilakukan perlakuan tetapi diukur. Penelitian ini berjudul
\end{abstract}

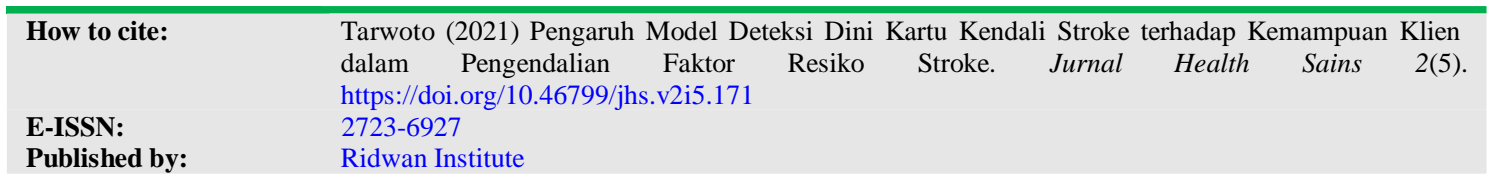


pengaruh model deteksi dini melalui edukasi kartu kendali stroke terhadap kemampuan klien dalam pengendalian faktor

Kata Kunci:

stroke; faktor resiko stroke; edukasi kartu kendali stroke (KKS) resiko stroke. Sampel penelitian ini sebanyak 80 orang untuk kelompok kontrol dan 80 orang kelompok intervensi dengan kriteria sampel penderita dengan factor resiko stroke. Tempat penelitian di Jakarta Selatan dengan lama penelitian 4 bulan.

\section{Pendahuluan}

Stroke merupakan penyakit degeneratif yang saat ini semakin banyak terjadi. Hal ini disebabkan adanya perubahan gaya hidup masyarakat yang kurang sehat, seperti makin berkurangnya aktivitas, pola makan yang tidak sehat, istirahat yang kurang, dan banyak faktor lainnya (Suiraoka, 2012). Menurut Yayasan Stroke Indonesia (Nur, 2017) jumlah penderita stroke di Indonesia menduduki rangking pertama dan terbanyak di Asia.

Hasil riskesdas tahun 2018 menunjukkan adanya peningkatan prevalensi penyakit tidak menular, termasuk penyakit stroke yaitu dari 7\% naik menjadi 10,9\% (Kemenkes, 2018). Angka ini diprediksi akan terus naik seiring perubahan sosial masyarakat. Tingginya angka kesakitan ini menjadi kekwatiran sendiri bagi setiap individu, karena resiko stroke menjadikan produktifitas individu akan menurun (Riskesdas, 2013).

Penyakit stroke adalah penyakit yang disebabkan karena gangguan pembuluh darah otak, yang kemudian otak menjadi kekurang oksigen, iskemia bahkan dapat mengakibatkan infak serebal (Farhan, 2018). Pada keadaan ini otak akan mengalami kerusakan dan terganggunya fungsi otak. Pasien yang mengalami stroke akan mengalami gejala yang khas diantaranya gangguan bicara (pelo), gangguan motorik (hemiparesis), kerusakan pada otot-otot wajah (gangguan Nerves VII), gangguan penglihatan, menelan. Tingkat keparahan dari gejala tersebut tergantung pada keadaan seberapa besar tingkat kerusakan pada organ saraf (Hana Yandrasary \& Milkhatun, 2019). Pada kondisi stroke yang inkomplit, pasien mungkin akan pulih sedia kala, walaupun tidak $100 \%$ seperti semula, tetapi pada kondisi implomplit maka akan terjadi gangguan yang bersifat permanen yaitu adanya gejala sisa yang tidak dapat pulih.

Dengan demikian upaya pencegahan stroke akan sangat berarti karena jika sudah terjadi serangan stroke yang komplit sudah dipastikan tidak dapat sembuh seperti semula.

Faktor resiko terjadinya stroke saat ini sudah dapat diidentifikasi yaitu hipertensi, obesitas, diabetes melitus, merokok, kurang ativitas, hiperkolesterol (Dinata et al., 2013). Sehingga upaya-upaya pencegahan terjadinya stroke sesungguhnya akan lebih mudah dilakukan. Namun demikian, tidak semua pasien menyadari hal tersebut bahkan walaupun tahu tentang faktor resiko bisa jadi menjadi abai.

Salah satu alternatif yang meungkin menjadi solusi upaya pencegahan stroke adalah adanya kartu kendali faktor risiko stroke (Isnaini, 2009). Kartu ini berisikan faktor risiko stroke yang kemudian dapat mengidentifikasi tingkat resiko yaitu risiko rendah, sedang, perhatian dan tinggi. Sehubungan dengan hal tersebut, peneliti tertarik untuk melakukan kajian lebih mendalam apakah kartu kendali risiko stroke efektif dalam mengendalikan faktor resiko stroke, sehingga peneliti mengambil judul "Pengaruh model deteksi dini melalui edukasi kartu kendali stroke terhadap kemampuan klien dalam pengendalian faktor risiko stroke “.

Stroke merupakan penyakit neurologik yang disebabkan karena gangguan pembuluh darah di otak sehingga menimbulkan gejala yang khas (Hall, 2009). Ada beberapa faktor 
penyebab stroke yaitu jenis kelamin, usia, hipertensi, penyakit DM, perokok, kurang aktivitas, dan lain-lain (Utami, 2015). Pada kenyataanya faktor penyebab stroke dibagi dua yaitu faktor yang dapat diubah dan faktor yang tidak dapat diubah (Muswanti, 2016). Penelitian ini ingin membuktikan apakah model deteksi dini dengan edukasi kartu kendali stroke dapat memengaruhi kemampuan dalam pengendalian faktor risiko stroke (Wayunah \& Saefulloh, 2017).

Tujuan umum penelitian ini adalah mengidentifikasi pengaruh model deteksi dini edukasi kartu kendali stroke terhadap kemampuan pengendalian faktor resiko stroke.

Manfaat penelitian untuk masyarakat Memberi masukan bagi pihak pelayanan kesehatan tentang manfaat model deteksi dini dengan edukasi kartu kendali stroke dalam pengendalian faktor risiko stroke.

\section{Metode Penelitian}

Pada penelitian ini menggunakan Quasi-Experimental dengan pendekatan Pretest-Posttest with Control Group Desaign. Pada desain ini peneliti melakukan penilaian pada kelompok kontrol dan kelompok intervensi sebelum edukasi Kartu Kendali Stroke (KKS). Kelompok intervensi dilakukan perlakukan dengan diberikan edukasi KKS kemudian diukur (post test) kemapuan dalam pengendalian factor risiko stroke sedangkan kelompok kontrol tidak dilakukan perlakuan tetapi diukur (post test) (Dimitrov \& Rumrill Jr, 2003).

Populasi pada penelitian ini adalah semua penderita risiko tinggi stroke yang menjadi anggota Posbindu di wilayah Jakarta Selatan. Penelitian ini akan dilakukan di Wilayah Puskesmas Jakarta Selatan. Pelaksanaan penelitian direncanakan pada bulan Agustus s.d November 2019 selama 4 bulan.

\section{Hasil dan Pembahasan}

a. Teridentifikasinya karakteristik jenis kelamin, usia, tingkat pendidikan dan factor risiko stroke pada kelompok intervensi dan kelompok control.

\section{Tabel 1}

\begin{tabular}{|c|c|c|}
\hline Variabel & $\mathbf{f}$ & $\%$ \\
\hline \multicolumn{3}{|c|}{ Jenis Kelamin } \\
\hline Laki-laki & 32 & 20.0 \\
\hline Perempuan & 128 & 80.0 \\
\hline \multicolumn{3}{|l|}{ Umur } \\
\hline \multicolumn{3}{|l|}{$<20$ tahun } \\
\hline 20-35 tahun & 4 & 2.5 \\
\hline$>35$ tahun & 156 & 97.5 \\
\hline \multicolumn{3}{|l|}{ Pendidikan } \\
\hline SD & 58 & 36.3 \\
\hline SMP & 21 & 13.1 \\
\hline SMA & 59 & 36.9 \\
\hline PT & 22 & 13.8 \\
\hline \multicolumn{3}{|c|}{ Faktor risiko } \\
\hline Rendah & 110 & 68.8 \\
\hline Tinggi & 50 & 31.3 \\
\hline
\end{tabular}

Pada tabel 1 dapat diketahui bahwa berdasarkan jenis kelamin, ada sebanyak $32(20 \%)$ responden dengan jenis kelamin laki-laki dan 128 (80\%) responden dengan jenis kelamin perempuan. Berdasarkan umur, ada sebanyak $4(2,5 \%)$ responden dengan umur 20 sampai dengan 35 tahun, dan $156(97,5 \%)$ responden dengan umur di atas 35 tahun. Dilihat dari pendidikan, ada sebanyak $58 \quad(36,3 \%)$ responden dengan tingkat pendidikan SD, $2(13,1 \%)$ berpendidikan SMP, $59 \quad(36,9 \%)$ berpendidikan SMA dan sisasnya 22 $(13,8 \%)$ berpendidikan perguruan tinggi. Berdasarkan faktor risiko, ada sebanyak $110(68,8 \%)$ responden dengan risiko rendah dan sisanya sebanyak 50 (31,3\%) responden dengan risiko tinggi. 
Tabel 2

\begin{tabular}{|c|c|c|c|c|}
\hline \multirow[t]{2}{*}{ Variabel } & \multicolumn{2}{|c|}{$\begin{array}{c}\text { Kelompok } \\
\text { Kontrol }\end{array}$} & \multicolumn{2}{|c|}{$\begin{array}{l}\text { Kelompok } \\
\text { Intervensi }\end{array}$} \\
\hline & $\mathbf{F}$ & $\%$ & f & $\%$ \\
\hline \multicolumn{5}{|l|}{$\begin{array}{l}\text { Jenis } \\
\text { Kelamin } \\
\end{array}$} \\
\hline Laki-laki & 14 & 17.5 & 18 & $22.5 \%$ \\
\hline Perempuan & 66 & 82.5 & 62 & $77.5 \%$ \\
\hline \multicolumn{5}{|l|}{ Umur } \\
\hline \multicolumn{5}{|l|}{$<20$ tahun } \\
\hline $\begin{array}{l}20-35 \\
\text { tahun }\end{array}$ & 2 & 2.5 & 2 & 2.5 \\
\hline$>35$ tahun & 78 & 97.5 & 78 & 97.5 \\
\hline \multicolumn{5}{|l|}{$\begin{array}{l}\text { Pendidik } \\
\text { an }\end{array}$} \\
\hline SD & 29 & 36.3 & 29 & 36.3 \\
\hline SMP & 6 & 7.5 & 15 & 18.8 \\
\hline SMA & 36 & 45.0 & 23 & 28.7 \\
\hline $\mathrm{PT}$ & 9 & 11.3 & 13 & 16.3 \\
\hline \multicolumn{5}{|l|}{$\begin{array}{l}\text { Faktor } \\
\text { risiko }\end{array}$} \\
\hline Rendah & 51 & 63.7 & 59 & 73.8 \\
\hline Tinggi & 29 & 36.3 & 21 & 26.3 \\
\hline
\end{tabular}

Berdasarkan jenis kelamin, ada sebanyak $14(17,5 \%)$ responden dengan jenis kelamin laki-laki pada kelompok kontrol dan 18 (22,5\%) pada kelompok intervensi. Sedangkan untuk responden dengan jenis kelamin perempuan, ada sebanyak $66(82,5 \%)$ pada kelompok kontrol dam 62 (77,5\%) pada kelompok intervensi. Jika dilihat berdasarkan umur, ada sebanyak $2(2,5 \%)$ responden dengan umur 20 sampai dengan 35 tahun pada kelompok kontrol dan dan kelompok intervensi. Untuk responden dengan umur lebih dari 35 tahun ada sebanyak 78 (97,5\%) pada kelompok kontrol maupun kelompok intervensi. Berdasarkan tingkat pendidikan, diketahui ada sebanyak 29 $(36,3 \%)$ responden dengan tingkat pendidikan SD pada kelompok kontrol dan juga kelompok intervensi. Selanjutnya responden dengan tingkat pendidikan SMP ada sebanyak $6(7,5 \%)$ pada kelompok kontrol dan $15(18,8 \%)$ pada kelompok intervensi. Untuk tingkat pendidikan SMA ada sebanyak $36(45 \%)$ responden pada kelompok kontrol dan $23(28,7 \%)$ pada kelompok intervensi. Terakhir untuk pendidikan perguruan tinggi ada $9(11,3 \%)$ pada kelompok kontrol dan $13(16,3 \%)$ pada kelompok intervensi. Jika dilihat berdasarkan faktor risiko, diketahui ada sebanyak $51(63,7 \%)$ responden dengan risiko rendah pada kelompok kontrol dan $21(26,3 \%)$ pada kelompok intervensi. Terakhir responden dengan risiko tinggi ada sebanyak 29 (36,3\%) pada kelompok kontrol dan $21(26,3 \%)$ pada kelompok intervensi.

b. Teridentifikasinya kemampuan dalam pengendalian faktor resiko stroke pada kelompok kontrol dan kelompok intervensi.

\section{Tabel 3}

\begin{tabular}{lcc}
\hline Variabel & f & \% \\
\hline $\begin{array}{l}\text { Kemampuan } \\
\text { pengendalian faktor } \\
\text { risiko }\end{array}$ & & \\
\hline Kurang & 150 & 93.8 \\
\hline Baik & 10 & 6.3 \\
\hline
\end{tabular}

Berdasarkan tabel di atas, diketahui bahwa responden dengan kemampuan pengendalian faktor risiko kurang ada sebanyak $150 \quad(93,8 \%)$ dan responden dengan kemampuan pengendalian faktor risikobaik ada sebanyak $10(6,3 \%)$.

\section{Tabel 4}

\begin{tabular}{lcccc}
\hline Variabel & $\begin{array}{c}\text { Kelompok } \\
\text { Kontrol }\end{array}$ & \multicolumn{2}{c}{$\begin{array}{c}\text { Kelompok } \\
\text { Intervensi }\end{array}$} \\
\hline & f & $\%$ & f & \% \\
\hline $\begin{array}{l}\text { Kemampuan } \\
\text { pengendalian } \\
\text { faktor risiko }\end{array}$ & & & & \\
\hline Kurang & 76 & 95.0 & 74 & 92.5 \\
\hline Baik & 4 & 5.0 & 6 & 7.5 \\
\hline
\end{tabular}

Dilihat berdasarkan kelompok responden, ada sebanyak $76 \quad(95 \%)$ responden dengan kemampuan pengendalian faktor risiko kurang pada kelompok kontrol dan 74 (92,5\%) pada 
kelompok intervensi. Untuk responden dengan kemampuan pengendalian faktor risiko baik sebanyak 4 (5\%) pada

kelompok kontrol dan 6 (7,5\%) pada kelompok intervensi.

c. Teridentifikasinya perbedaan kemampuan dalam pegendalian faktor risiko stroke pada kelompok kontrol dan kelompok intervensi.

Tabel 4

\begin{tabular}{lcccccc}
\hline \multirow{2}{*}{ Variabel } & \multicolumn{2}{c}{$\begin{array}{c}\text { Kelompok } \\
\text { Kontrol }\end{array}$} & \multicolumn{2}{c}{$\begin{array}{c}\text { Kelompok } \\
\text { Intervensi }\end{array}$} & Total & $\begin{array}{c}\boldsymbol{P} \text { - } \\
\text { value }\end{array}$ \\
\cline { 2 - 5 } & $\mathbf{f}$ & $\boldsymbol{\%}$ & $\mathbf{f}$ & $\boldsymbol{\%}$ & & \\
\hline $\begin{array}{l}\text { Kemampuan } \\
\text { pengendalian } \\
\text { faktor risiko }\end{array}$ & & & & & & \\
\hline Kurang & 76 & 50,7 & 74 & 49,3 & 150 & 0,744 \\
\hline Baik & 4 & 40,0 & 6 & 60,0 & 10 & \\
\hline
\end{tabular}

Berdasarkan tabel di atas didapatkan bahwa proporsi kemampuan yang kurang dalam pengendalian faktor risiko stroke pada kelompok kontrol sebelum intervensi adalah $50,7 \%$ sedangkan yang baik $40 \%$. Pada kelompok intervensi sebelum intervensi, diketahui ada sebanyak 49,3\% kemampuan kurang dan 60\% kemampuan baik. Hasil uji statistik didapatkan nilai pvalue sebesar $0,774(>0,05)$ yang artinya tidak terdapat perbedaan antara kemampuan pengendalian faktor risiko stroke pada kelompok kontrol dan intervensi sebelum intervensi.

Tabel 5

\begin{tabular}{|c|c|c|c|c|c|c|}
\hline \multirow[t]{2}{*}{ Variabel } & \multicolumn{2}{|c|}{$\begin{array}{c}\text { Kelompok } \\
\text { Kontrol }\end{array}$} & \multicolumn{2}{|c|}{$\begin{array}{l}\text { Kelompok } \\
\text { Intervensi }\end{array}$} & \multirow[t]{2}{*}{ Total } & \multirow{2}{*}{$\begin{array}{l}P \text { - } \\
\text { val } \\
\text { ue }\end{array}$} \\
\hline & $\mathbf{f}$ & $\%$ & f & $\%$ & & \\
\hline \multicolumn{7}{|l|}{$\begin{array}{l}\text { Kemampuan } \\
\text { pengendalian } \\
\text { faktor risiko }\end{array}$} \\
\hline Kurang & 76 & 50,7 & 74 & 49,3 & 150 & 0,744 \\
\hline Baik & 4 & 40,0 & 6 & 60,0 & 10 & \\
\hline
\end{tabular}

Berdasarkan tabel di atas didapatkan bahwa proporsi kemampuan yang kurang dalam pengendalian faktor risiko stroke kurang pada kelompok kontrol setelah intervensi adalah 50,7\% sedangkan yang baik 40\%. Pada kelompok intervensi setelah intervensi diketahui ada sebanyak
49,3\% responden dengan kemampuan kurang dan $60 \%$ dengan kemampuan baik. Hasil uji statistik didapatkan nilai p-value sebesar $0,774(>0,05)$ yang artinya tidak terdapat perbedaan antara kemampuan pengendalian faktor risiko stroke pada kelompok kontrol dan intervensi setelah intervensi.

d. Teridentifikasinya pengaruh model deteksi dini melalui edukasi kartu kendali stroke terhadap kemampuan faktor resiko stroke pada kelompok intervensi.

\section{Tabel 6}

\begin{tabular}{|c|c|c|c|c|c|}
\hline \multirow{2}{*}{$\begin{array}{l}\text { Kemampuan } \\
\text { pengendalian } \\
\text { faktor risiko }\end{array}$} & \multirow[b]{2}{*}{ Coef } & \multirow[b]{2}{*}{ OR } & \multicolumn{2}{|c|}{$95 \% \mathrm{CI}$} & \multirow[b]{2}{*}{$\begin{array}{c}\text { p- } \\
\text { value }\end{array}$} \\
\hline & & & lower & upper & \\
\hline \multicolumn{6}{|l|}{$\begin{array}{l}\text { Kartu } \\
\text { kendali sehat }\end{array}$} \\
\hline \multicolumn{6}{|l|}{$\begin{array}{l}\text { Tidak } \\
\text { diberikan }\end{array}$} \\
\hline Diberikan & $\underline{-0.373}$ & $\underline{0.689}$ & $\underline{0.323}$ & 1.469 & $\underline{0.334}$ \\
\hline \multicolumn{6}{|l|}{$\begin{array}{l}\text { Jenis } \\
\text { Kelamin }\end{array}$} \\
\hline \multicolumn{6}{|l|}{ Laki-laki } \\
\hline Perempuan & -0.469 & $\underline{0.625}$ & 0.254 & 1.539 & $\underline{0.307}$ \\
\hline \multicolumn{6}{|l|}{ Umur } \\
\hline \multicolumn{6}{|l|}{ 20-35 tahun } \\
\hline$>35$ tahun & -1.408 & $\underline{0.245}$ & $\underline{0.030}$ & $\underline{2.003}$ & $\underline{0.189}$ \\
\hline & & & & & 0.809 \\
\hline \multicolumn{6}{|l|}{ Pendidikan } \\
\hline \multicolumn{6}{|l|}{ SD } \\
\hline SMP & -0.475 & 0.622 & 0.167 & 2.317 & 0.479 \\
\hline SMA & -0.238 & 0.788 & 0.331 & 1.877 & 0.591 \\
\hline $\mathrm{PT}$ & 0.143 & 1.154 & 0.374 & 3.555 & 0.803 \\
\hline \multicolumn{6}{|l|}{ Faktor risiko } \\
\hline \multicolumn{6}{|l|}{ Rendah } \\
\hline Tinggi & 0.120 & 1.128 & 0.511 & 2.490 & 0.766 \\
\hline Konstanta & 0.858 & - & - & - & 0.477 \\
\hline
\end{tabular}

Hasil uji statistik didapatkan bahwa tidak terdapat pengaruh deteksi dini melalui edukasi kartu kendali stroke terhadap kemampuan faktor risiko stroke pada kelompok intervensi ( $\mathrm{p}$-value>0,05) setelah dikontrol variabel lainnya (jenis kelamin, usia, tingkat pendidikan, dan faktor risiko stroke).

\section{Kesimpulan}

Karakteristik responden berdasarkan umur sebagian besar usia diatas 35 tahun $(97,5 \%)$. Jenis kelamin responden sebagian besar perempuan $(82,5 \%)$ dan tingkat 
pendidikan sebagian besar berpendidikan SMA $(45 \%)$.

Karakteristik responden berdasarkan faktor resiko, diketahui ada sebanyak 63,7\% responden dengan resiko rendah pada kelompok kontrol, dan 73,8\% pada kelompok intervensi. Selanjutnya ada $36,3 \%$ responden dengan faktor risiko tinggi pada kelompok kontrol dan 26,3\% pada kelompok intervensi.

Kemampuan responden dalam pengendalian faktor risiko, berdasarkan tingkat pengetahuan pada pre test baik kelompok kontrol dan kelompok intervensi $100 \%$ kurang. Pada hasil post-test tingkat kemampuan pengetahuan dalam mengontrol faktor resiko stroke pada kelompok intervensi yang baik 42,5 \% dan kurang baik 57,5\%, sedangkan pada kelompok kontrol berpengetahuan baik $6,25 \%$ dan yang berpengetahuan kurang 93,75\%. Hal ini berarti ada kenaikan pengetahauan pada kelompok intervensi sebanyak 42,5\% dan pada kelompok kontrol terjadi peningkatan pengetahuan sebesar $6,25 \%$.

Hasil uji statistik menunjukkan adanya perbedaan yang signifikan antara kemampuan pengetahuan dan sikap terhadap kemampuan dalam pengendalian faktor resiko stroke setelah dilakukan edukasi dan kartu kendali stroke (nilai $\mathrm{p}=0,001$ ).

Responden yang diberikan edukasi kartu kendali stroke mempunyai peluang peningkatan kemampuan pengetahuan $11 \mathrm{kali}$ lebih baik dalam pengendalian faktor resiko stroke dibandingkan dengan yang tidak, setelah dikontrol dengan variabel usia dan sikap. Sedangkan responden untuk variabel sikap bahwa responden yang diberikan edukasi kartu kendali stroke mempunyai peluang peningkatan sikap 1 kali lebih baik dalam pengendalian faktor resiko stroke dibandingkan dengan yang tidak, setelah dikontrol variable usia dan pengatahuan, dengan nilai $\mathrm{P}$ value $=0,0001$. $\mathrm{R}$ square $=$ 0,278 , artinya variabel pelaksanaan model deteksi dini edukasi kartu kendali stroke dapat menjelaskan variasi kemampuan pengetahuan dan sikap sebesar $27,8 \%$ dan sisanya dijelaskan oleh variabel lain.

\section{BIBLIOGRAFI}

Chairunnisa, W. R. (2020). Faktor Risiko Yang Berhubungan Dengan Kejadian Diabetes Melitus Pada Masyarakat Urban Dan Masyarakat Pesisir Di Kota Medan. Universitas Islam Negeri Sumatera Utara. Google Scholar

Dimitrov, D. M., \& Rumrill Jr, P. D. (2003). Pretest-Posttest Designs And Measurement Of Change. Work, 20(2), 159-165. Google Scholar

Dinata, C. A., Syafrita, Y., \& Sastri, S. (2013). Gambaran Faktor Risiko Dan Tipe Stroke Pada Pasien Rawat Inap Di Bagian Penyakit Dalam Rsud Kabupaten Solok Selatan Periode 1 Januari 2010-31 Juni 2012. Jurnal

Kesehatan Andalas, 2(2), 57-61. Google Scholar

Farhan, Z. (2018). Pengaruh Latihan Vokal Terhadap Perubahan Kemampuan Menelan Pada Pasien Stroke Infark Di Ruang Cempaka Rumah Sakit Umum Daerah Dr. Slamet Garut Tahun 2015. Jurnal Soshum Insentif, 43-55. Google Scholar

Hall, J. W. (2009). Uncommon Defense: Indian Allies In The Black Hawk War. Harvard University Press. Google Scholar

Hana Yandrasary, Y., \& Milkhatun, M. (2019). Analisis Praktik Klinik Keperawatan Pada Klien Stroke Non Hemoragik Dengan Intervensi Inovasi Oral Hygiene Dengan Clorhexidine Untuk Mengurangi Infeksi Rongga Mulut Di Ruang Stroke Centre Afi Rsud Abdul Wahab Sjahranie Samarinda. Google Scholar

Isnaini, S. (2009). Apar (Alat Pemadam Api Ringan) Dan Instalasi Hydrant Sebagai 
Salah Satu Upaya Pencegahan Dan Penanggulangan Kebakaran Di Area Pabrik I Pt. Petrokimia Gresik. Google Scholar

Kemenkes, R. I. (2018). Hasil Utama Riskesdas 2018. In Online) Http://Www. Depkes. Go. Id/Resources/Download/InfoTerkini/Materi_Rakorpop_2018/Hasil\% 20riskesdas (Vol. 202018). Google Scholar

Muswanti, I. J. (2016). Hubungan Pengetahuan Dan Sikap Dengan Perilaku Pencegahan Komplikasi Stroke Pada Penderita Hipertensi Usia $\leq 45$ Tahun Di Puskesmas Ngemplak Simongan Kota Semarang. Universitas Negeri Semarang. Google Scholar

Nur, S. (2017). Hubungan Pengetahuan Dan Sikap Penderita Stroke Tentang Hipertensi Dengan Upaya Pencegahan Stroke Berulang Di Poliklinik Saraf
Rsud Muhammad Zein Painan Tahun 2017. Universitas Andalas. Google Scholar

Riskesdas. (2013). Riskesdas 2013. In Jakarta Kementeri Kesehat Ri (Vol. 6). Google Scholar

Suiraoka, I. P. (2012). Penyakit Degeneratif. Yogyakarta: Nuha Medika, 45-51. Google Scholar

Utami, F. R. (2015). Hubungan Upaya Pencegahan Terhadap Kejadian Stroke Berulang Pada Penderita Stroke (Studi Kasus Pada Penderita Stroke Di Poli Saraf Rawat Jalan Rsd Dr. Soebandi Jember, Tahun 2014). Google Scholar

Wayunah, W., \& Saefulloh, M. (2017). Analisis Faktor Yang Berhubungan Dengan Kejadian Stroke Di Rsud Indramayu. Jurnal Pendidikan Keperawatan Indonesia, 2(2), 65-76. Google Scholar

\section{Copyright holder:}

Tarwoto (2021)

\section{First publication right:}

Jurnal Health Sains

This article is licensed under: 